\title{
AODV-PNT Performance Study with Added Factor Number of Neighbor Nodes on VANET
}

\author{
Grezio Arifiyan ${ }^{1}$, Supeno Djanali ${ }^{1}$, Radityo Anggoro ${ }^{1}$
}

\begin{abstract}
VANET (Vehucular Ad hoc Network) is a development of Mobile Ad hoc Network or often called MANET. The topology of VANET can change rapidly because of the movement of the node so that the topology can change dynamically, otherwise there is an interesting problem to be investigated on VANET ie connectivity between nodes. AODV protocol routing is further developed one of them is AODV-PNT, by adding prediction of node trend (Prediction Node Trend) by calculating TWR (Total Weight of The Route). In this study the factors - factors in determining TWR.
\end{abstract}

Keywords-MANET, VANET, AODV, AOMDV, AODV-PNT, TWR, W, Neighboring Nodes.

\section{INTRODUCTION}

VANET (Vehicular ad-hoc Network) is a new technology used for inter-vehicle communication with the addition of devices. VANET is an important part in the application of ITS (Intelligent Transportation System) [1].

AODV (Ad hoc On-Demand Distence Vector) is a routing protocol that will create a routing route only when it sends packets often called on-demand driven routing protocols. The main characteristic of VANET is a fast moving (node) vehicle, such rapid movement can affect topology changes rapidly [2].

With a very fast topology change it is necessary to select a better transmission connection between vehicles (nodes) when making the route discovery, so the connection can last long. AODV-PNT adds several factors in route selection to choose the best route, it is hoped that with a good route it can boost the PDR (packet delivery ratio), reduce link failure and decrease routing overhead in dynamic topology.

Factors used as TWR calculations on AODV-PNT protocols can be further developed by adding other factors so as to improve the quality of routing route selection, some factors that can be added include signal strength of each node or neighboring node density, With the addition of parameters is expected to select the routing route can be more optimal. The method used to detect neighbor nodes uses HELLO messages sent periodically to find neighbor nodes at a time [3].

\footnotetext{
${ }^{1}$ Grezio Arifiyan, Supeno Djanali, and Radityo Anggoro are with Department of Chemical Engineering, Faculty of Industrial Engineering, Institut Teknologi Sepuluh Nopember (ITS), Kampus ITS Sukolilo, Surabaya 60111, Indonesia. E-mail: grez.arifiyan@gmail.com; supeno@its.ac.id; onggo.informatika@gmail.com.
}

\section{EXPERIMENTAL}

\section{A. VANET (Vehicular ad-hoc Network)}

VANET (Vehicular ad-hoc Network) is a new technology used for inter-vehicle communication with the addition of devices [1]. VANET is an important part in the application of ITS (Intelligent Transportation System).

\section{B. AODV (Ad hoc On-Demand Distence Vector)}

AODV (Ad hoc On-Demand Distence Vector) is a routing protocol that will create a routing route only when it sends packets often called on-demand driven routing protocols. The main characteristic of VANET is a fast moving (node) vehicle, such rapid movement can affect topology changes rapidly [2].

\section{AODV-VANET}

$\mathrm{Xi} \mathrm{Yu}$ et al proposed a new routing protocol called AODV- VANET [4], in which the protocol added vehicle movement information into the process of route discovery based on AODV (Ad hoc On-Demand Distance Vector). TWR (Total of Weight of the Route) was introduced to select the best route together with the estimated end time to minimize the link breakages. Based on the modifications made, the AODV-VANET protocol is capable of achieving better routing performance compared to AODV without modification.

\section{AODV-PNT}

With a very fast topology change it is necessary to select a better transmission connection between vehicles (nodes) when making the route discovery, so the connection can last long. AODV-PNT adds several factors in route selection to choose the best route, it is hoped that with a good route it can boost the PDR (packet delivery ratio), reduce link failure and decrease routing overhead in dynamic topology [4].

Factors used as TWR calculations on AODV-PNT protocols can be further developed by adding other factors so as to improve the quality of routing route selection, some factors that can be added include signal strength of each node or neighboring node density, With the addition of parameters is expected to select the routing route can be more optimal. The method used to detect neighbor nodes uses HELLO messages sent periodically to find neighbor nodes at a time, figure 1 is AODV-PNT routing process. 


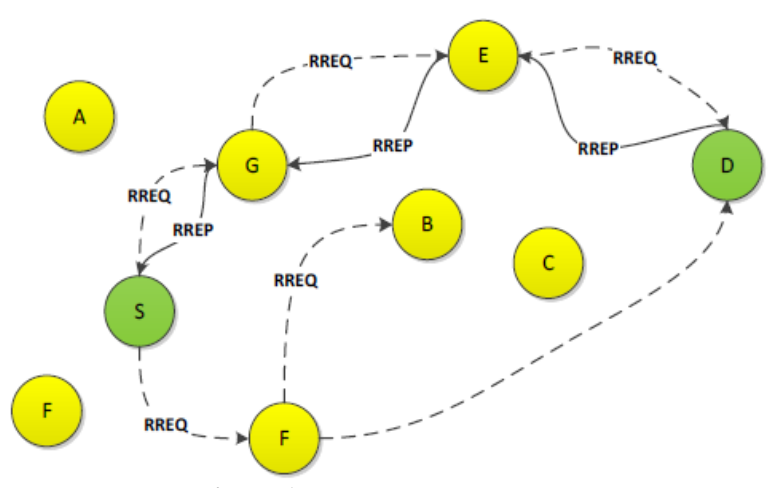

Figure 1. AODV-PNT Route Request.

In modifying the AODV protocol routing, a modified HELLO message (Table 1) is used to get information neighbour node.

TABLE 1.

HELLO MESSAGE.

\begin{tabular}{cccccc}
\hline \hline Type & Source ID & Speed & $\mathrm{x}$ & $\mathrm{y}$ & Neighbor Node \\
\hline \hline
\end{tabular}

TWR calculation, to get value Speed and acceleration of vehicle used physics formula. The direction of the vehicle process determines the direction of the vehicle using the coordinates of the ns- 2 simulator, then calculates the angle between the two way vehicles. Quality link between vehicles is the quality between nodes with maximum transmit distance. Neighbor node is the number of neighboring nodes of each node. Then to calculate the TWR using the formula (1).

$$
\begin{aligned}
& T W R=f_{s} \times\left|S_{n}-S_{d}\right|+f_{a} \times\left|A_{n}-A_{d}\right|+f_{d} \times \\
& \left|\theta_{n}-\theta_{d}\right|+f_{q} \times Q+f_{n} \times N
\end{aligned}
$$

Predic the Future The TWR of Node, with the dynamic VANET topology topology, then the selected next-hop has a chance of getting out of the transmision range on the next data packet, then calculating the future TWR of a node (3-5 seconds) With respect to the future value of TWR the expected route of the selected path has a long duration of connection time. Then the speed and acceleration using the existing physics formula. The direction of the vehicle is recalculated using $\mathrm{x}$ and $\mathrm{y}$ coordinates. Link quality is recalculated because there is a change in value. The number of neighboring nodes is considered fixed.

After the TWR and futur TWR values are obtained, the relay node is selected if (Table 2 ):

TABLE 2.

CHOOSE RELAY NODE.

\begin{tabular}{lcll}
\hline \hline Current TWR & State & Future TWR & Judgement \\
\hline Optimal & Instable & Better & Relay Node \\
Optimal & Stable & $\backslash$ & Relay Node \\
Suboptimal & Instable & Better & Relay Node \\
Suboptimal & Stable & $\backslash$ & Relay Node \\
& Other Case & & Abandon \\
\hline \hline
\end{tabular}

\section{RESUltS AND DISCUSSION}

Simulation result, The trials used 30 grid scenarios with random mobility scenarios on grid maps with an area of
$800 \mathrm{~m} \times 800 \mathrm{~m}$ with nodes of 10, 20, 50, 75 and 100 maximum velocities of each node being $15 \mathrm{~m} / \mathrm{s}$. PDR protocol AODV-Mod has a better performance compared to the AODV-PNT protocol although the increase is not significant. At the number of nodes 10, 30, 50 and 75 PDR the AODV-MNS protocol is superior about 0.7\% $-13 \%$ better than the AODV-PNT protocol, figure 2.

Average end-to-end delay is the calculation used to know the average value of time required by the packet to arrive from source to destination. Comparison of AODV, AODVPNT and AODV-Modi average end-to-end delay calculation can be seen in Figure 2. In the number of node 10 protocols AODV-PNT and AODV-Mod have a high delay compared with the original AODV, 3.39 seconds for AODV-PNT and 3.13 seconds delay generated AODVMod. At low density nodes AODV-PNT and AODV-Mod require considerable time in route discovery, the delay generated by AODV-Mod is smaller by 0.25 seconds. On the number of nodes 30, 50, 75 and 100 delay generated by the AODV-Mod protocol smaller than the original AODV protocol or AODV-PNT protocol.

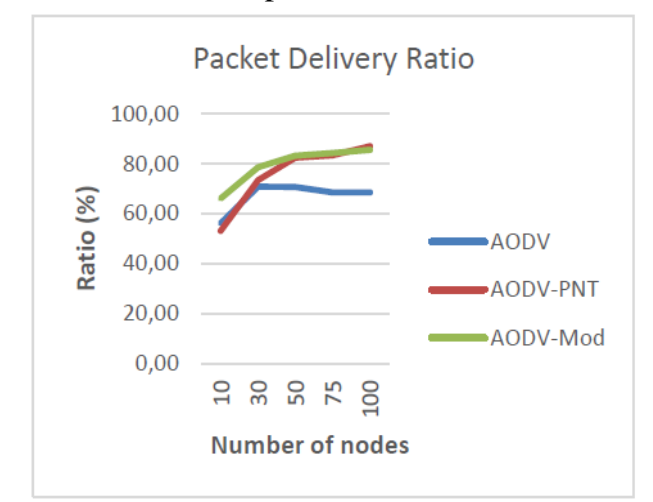

Figure 2. Packet Delivery Ratio

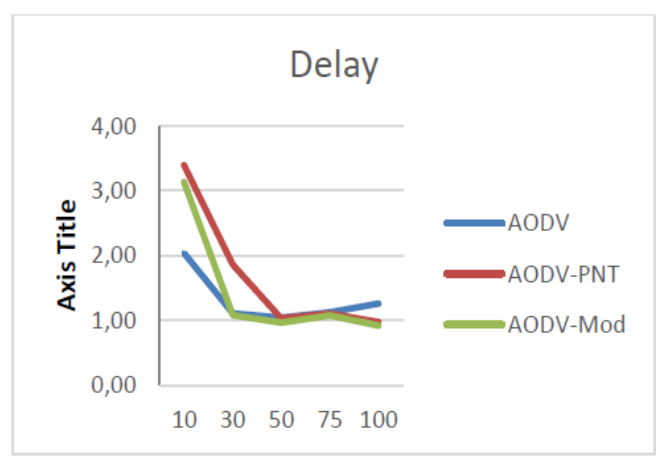

Figure 3. Delay

Routing overhead is the number of transmitted routing packets, the transmitted routing packet consists of RREQ, RREP, and RERR. Based on figure 4 the overhead routing on AODV-Mod is higher than the original AODV-PNT protocol, the average RO increase is approximately 106.06 packets, the highest RO difference when the number of nodes 30 and 75.

Hop count is the number of point-to-point links in the transmission path, the average hop count result can be seen in figure 5. Based on the modulated average hop protocol 
AODV-Mod has a considerable number of hops compared to the AODV-PNT protocol, with an average difference of approximately 0.23 hops longer, at the number of nodes 50 and 100 the number of hops generated by the AODV protocol -Mod 0,002-0,16 hop smaller than AODV-PNT, decrease in hop count can be caused due to relay node selected when path formation is few.

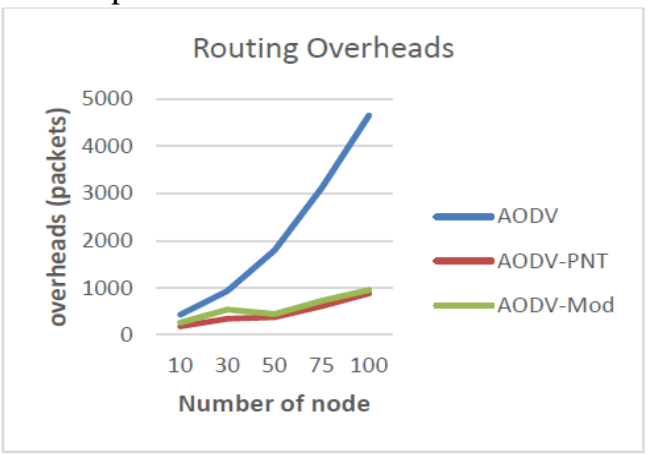

Figure 4. Routing Overhead

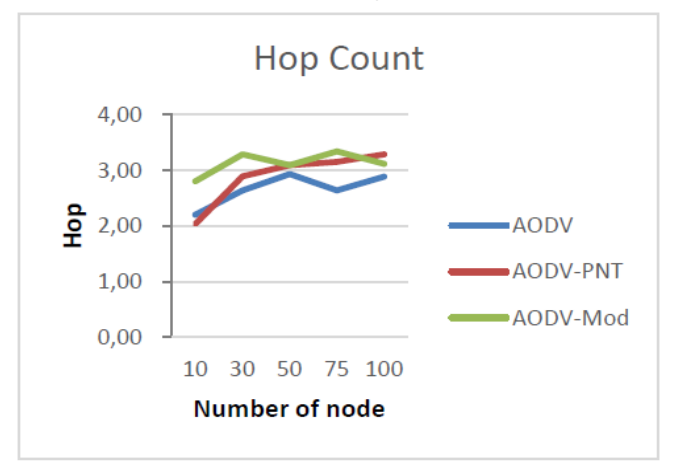

Figure 5. Hop Count

\section{CONCLUSION}

Packet delivery ratio AODV-Mod protocol routing is better than the AODV, AODV-PNT routing protocol. Packet delivery ratio from AODV-PNT and AODV-Mod increases with increasing vehicle density in the network.

The overhead routing and avarage delay on AODV-Mod is less than AODV because AODV-Mod performs stability selection against the next-hop node while AODV broadcasts so that each neighbor node receiving RREQ. The average hop count of AODV-Mod is greater than AODV-PNT 0.23 in the grid scenario and 0.19 in the real scenario. The average number of AODV-Mod hop counts is also larger than the original AODV with the difference in hop hop count in the grid scenario is 0.46 whereas in the real scenario the mean hop count difference is 0.66 .

\section{REFERENCE}

[1] S. Ur Rehman, M. A. Khan, T. A. Zia, and L. Zheng, "Vehicular Ad-Hoc Networks (VANETs) - An Overview and Challenges," $J$. Wirel. Netw. Commun., vol. 3, no. 3, pp. 29-38, 2013.

[2] C. E. Perkins and E. M. Royer, "Ad-hoc on-demand distance vector routing," in Proceedings WMCSA'99. Second IEEE Workshop on Mobile Computing Systems and Applications, 1999, pp. 90-100.

[3] R. S. Raw, V. Toor, and N. Singh, "Path Duration Analysis in Vehicular Ad Hoc Network,” Int. J. AdHoc Netw. Syst., vol. 2, no. 4, pp. 57-66, 2012.

[4] X. Yu, H. Guo, and W.-C. Wong, "A reliable routing protocol for VANET communications," in 2011 7th International Wireless Communications and Mobile Computing Conference, 2011, pp. 1748-1753. 